\title{
Formation of solid particles in synoptic-scale Arctic PSCs in early winter 2002/2003
}

\author{
N. Larsen ${ }^{1}$, B. M. Knudsen ${ }^{1}$, S. H. Svendsen ${ }^{1}$, T. Deshler ${ }^{2}$, J. M. Rosen ${ }^{2}$, R. Kivi ${ }^{3}$, C. Weisser ${ }^{4}$, J. Schreiner ${ }^{4}$, \\ K. Mauerberger ${ }^{4}$, F. Cairo ${ }^{5}$, J. Ovarlez ${ }^{6}$, H. Oelhaf ${ }^{7}$, and R. Spang ${ }^{8}$ \\ ${ }^{1}$ Danish Meteorological Institute, Lyngbyvej 100, DK-2100 Copenhagen, Denmark \\ ${ }^{2}$ University of Wyoming, Laramie, WY 82071, USA \\ ${ }^{3}$ Finnish Meteorological Institute, Arctic Research Centre, 99600 Sodankyla, Finland \\ ${ }^{4}$ Max-Planck-Institut für Kernphysik, Bereich Atmosphärenphysik, Postfach 103 980, 69029 Heidelberg, Germany \\ ${ }^{5}$ Istituto di Scienze dell'Atmosfera e del Clima, via Fosso del Cavaliere 100, 00133 Roma, CNR, Italy \\ ${ }^{6}$ Laboratoire de Météorologie Dynamique, CNRS-IPSL, Ecole Polytechnique, 91128 Palaiseau cedex, France \\ ${ }^{7}$ Forschungzentrum Karlsruhe, Institut für Meteorologie und Klimaforschung, Postfach 3640, 76021 Karlsruhe, Germany \\ ${ }^{8}$ Forschungzentrum Jülich, Institute for Chemistry and Dynamics of the Geosphere, Institute I: Stratosphere (ICG-I), 52425 \\ Jülich, Germany
}

Received: 2 February 2004 - Published in Atmos. Chem. Phys. Discuss.: 12 May 2004

Revised: 3 September 2004 - Accepted: 30 September 2004 - Published: 4 October 2004

\begin{abstract}
Polar stratospheric clouds (PSC) have been observed in early winter (December 2002) during the SOLVE II/Vintersol campaign, both from balloons carrying comprehensive instrumentation for measurements of chemical composition, size distributions, and optical properties of the particles, as well as from individual backscatter soundings from Esrange and Sodankylä. The observations are unique in the sense that the PSC particles seem to have formed in the early winter under synoptic temperature conditions and not being influenced by mountain lee waves. A sequence of measurements during a 5-days period shows a gradual change between liquid and solid type PSCs with the development of a well-known sandwich structure. It appears that all PSC observations show the presence of a background population of solid particles, occasionally mixed in with more optically dominating liquid particles. The measurements have been compared with results from a detailed microphysical and optical simulation of the formation processes. Calculated extinctions are in good agreement with SAGE-III measurements from the same period. Apparently the solid particles are controlled by the synoptic temperature history while the presence of liquid particles is controlled by the local temperatures at the time of observation. The temperature histories indicate that the solid particles are nucleated above the ice frost point, and a surface freezing mechanism for this is included in the model. Reducing the calculated freezing rates
\end{abstract}

Correspondence to: N. Larsen

(nl@dmi.dk) by a factor 10-20, the model is able to simulate the observed particle size distributions and reproduce observed $\mathrm{HNO}_{3}$ gas phase concentrations.

\section{Introduction}

It has been known for many years that polar stratospheric clouds (PSC) play a mandatory role for stratospheric ozone depletion (WMO, 2003), both as sites for activation of halogen compounds, through heterogeneous chemical reactions on surfaces of the cloud particles, and removal of reactive nitrogen by sedimentation of the nitric acid containing cloud particles. This last process, known as denitrification, will in most cases prolong the ozone depletion.

PSCs have been classified according to their optical properties as observed by lidar (Poole and McCormick, 1988; Browell et al., 1990; Toon et al., 1990), reflecting the physical state of the cloud particles, either composed of liquid supercooled ternary solutions (STS) (Tabazadeh et al., 1994; Carslaw et al., 1994; Schreiner et al., 1999a), of solid nitric acid trihydrate (NAT) (Hanson and Mauersberger, 1988; Voigt et al., 2000), or of ice. Only solid PSC particles can grow sufficiently in size to cause denitrification and much effort has been directed towards explaining their formation.

Based on laboratory measurements, homogeneous freezing of ice out of STS requires temperatures $3-4 \mathrm{~K}$ below the ice frost point temperature ( $\left.T_{\text {ice }}\right)$ (Koop et al., 2000). These 
temperatures may be commonly reached in mountain leewave conditions, leading to ice formation from STS and subsequent nucleation of nitric acid hydrates (e.g. Carslaw et al., 1998; Larsen et al., 2002). On synoptic scales in the Arctic stratosphere such low temperatures seldom occur, yet solid PSC particles are frequently observed (e.g. Toon et al., 2000). In addition, widespread denitrification without accompanying dehydration, i.e. without the involvement of ice PSCs, has been observed in Arctic winters (Fahey et al., 1990; Popp et al., 2001). While this cannot establish a freezing process above $\left(T_{\text {ice }}\right)$, since the ice phase may be very short lived compared to a long lived hydrate phase initiated by the ice, it is consistent with a freezing process above $T_{\text {ice }}$ which would help explain many observations of solid PSC particles (Drdla et al., 2002a). High number concentrations of small solid particles in equilibrium with the gas phase could be nucleated in mountain wave conditions (Tsias et al., 1999). Other investigations show PSCs to be dominated by liquid particles with only small concentrations of solid particles growing to large sizes; an observation which calls for a selective nucleation mechanism (Drdla et al., 2002b). Large nitric acid hydrate particles in small concentrations $<10^{-3} \mathrm{~cm}^{-3}$ with radii of 5-10 $\mu \mathrm{m}$ were frequently sampled in the Arctic winter 1999/2000 (Fahey et al., 2001), and it has been demonstrated how NAT particles could grow to such sizes under supersaturated conditions within a few days, leading to severe denitrification (Fueglistaler et al., 2002; Carslaw et al., 2002; Mann et al., 2002; Drdla et al., 2002a).

In this paper we describe and interpret a series of balloonborne experiments, performed from Kiruna, Sweden, and Sodankylä, Finland, in the very early stage of PSC formation in winter 2002/2003. The experiments were part of the joined US/European SOLVE-II/Vintersol campaign. For the first time a comprehensive set of measurements to characterize the chemical and physical state of PSC particles in early winter was obtained from Kiruna in synoptic-scale temperature history conditions without the influence of mountain leewaves.

\section{Meteorological conditions}

Small areas with stratospheric temperatures below the existence temperature $\left(T_{\mathrm{NAT}}\right)$ for nitric acid trihydrate (Hanson and Mauersberger, 1988) started to develop on the $550 \mathrm{~K}$ potential temperature surface around mid-November 2002 and grew larger in size around 20 November north-east of Scandinavia. At the end of November the cold area moved westward to the area between Greenland and Scandinavia. By the beginning of December it covered most of Greenland to the northern half of Scandinavia, reaching east of Novaya Zemlya. Areas with temperatures slightly below the ice frost point started to form around 4 December between Spitsbergen and Norway, lasting until around 10 December. Huge areas with temperatures below $T_{\text {NAT }}$ persisted through- out December in a stable vortex. Between 3 and 7 December, where the investigations were completed, northern Scandinavia was inside the polar vortex on the $550 \mathrm{~K}$ potential temperature surface. The meteorological situation in this period was characterized by a blocking high over the region, with very low surface winds, preventing the occurrence of mountain lee waves and strong temperature perturbations in stratospheric air parcels as they passed over the Norwegian mountains. This is also reflected by the fact that rise rates on all of the balloon flights shown below are quite steady or change gradually with time. If mountain waves had been present the rise rates would have oscillated in a regular fashion. Hence, no wave clouds were present at any level during the entire measurement period, and the PSC particles discussed in this paper can be assumed to have formed in synoptic scale cooling events over the North Atlantic.

\section{Measurements}

Two types of balloon-borne observations were performed from Esrange, Sweden $\left(67 . .^{\circ} 9 \mathrm{~N}, 21 .^{\circ} 1 \mathrm{E}\right)$ and Sodankylä, Finland (67. $\left.{ }^{\circ} 4 \mathrm{~N}, 26 .^{\circ} 6 \mathrm{E}\right)$ between 3 and 7 December 2002. One set of observations consisted of 7 profiles of backscatter ratio. The instrument, a backscatter sonde (Rosen and Kjome, 1991), carries pressure and temperature sensors and is equipped with a white light flash lamp and two photo detectors with filters, providing in-situ measurements of the vertical profile of aerosol backscatter ratios at $940 \mathrm{~nm}$ and $480 \mathrm{~nm}$. From the aerosol backscatter ratio (particulate to molecular) at these two wavelengths $\left(B_{940}\right.$ and $\left.B_{480}\right)$, a colour index, $B_{940} / B_{480}$, is calculated.

Results from four soundings at Esrange and three from Sodankylä are shown in Fig. 1. Based on experience from previous measurements (Larsen et al., 2002), liquid particle clouds are characterized by high backscatter and low and nearly constant colour indices (e.g. 4 December at $24 \mathrm{~km}$ ). This corresponds to type $1 \mathrm{~b}$ PSCs in the lidar classification (Toon et al., 1990). Solid particle clouds give rise to larger and more variable colour indices and lower backscatter (e.g. 6 December at $26 \mathrm{~km}$ ), equivalent to type 1a PSCs. During the first sounding on 3 December temperatures are just slightly below $T_{\mathrm{NAT}}$, and the profile is characterized by type 1a PSCs. Later, between 4 and 6 December, when temperatures drop further, type $1 \mathrm{~b}$ layers are observed at the lowest temperatures in the middle of the profiles. Temperatures above and below the type $1 \mathrm{~b}$ layer are still just slightly below $T_{\mathrm{NAT}}$, giving rise to the development of a "sandwich structure" with thick layers of type $1 \mathrm{~b}$ clouds surrounded by type 1a clouds at the bottom and top of the profile. "Sandwich" structures in PSC layers have previously been observed by lidar, e.g. Shibata et al. (1997, 1999), Shibata (1999), Stein et al., (1999), and Biele et al. (2001). At the end of this measurement period temperatures rise again, the type $1 \mathrm{~b}$ layers 


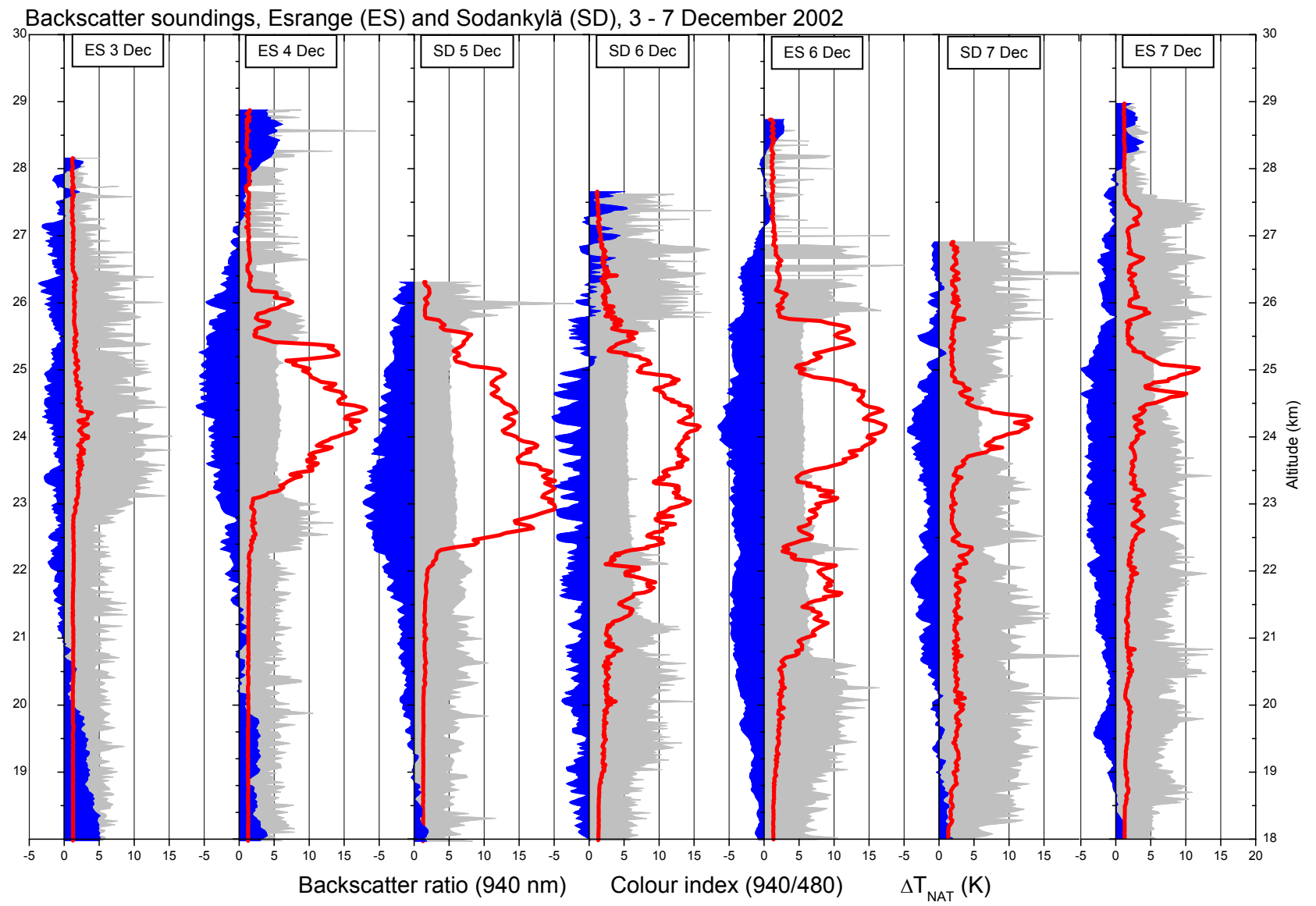

Fig. 1. A sequence of vertical profiles, obtained between 3 and 7 December 2002 from Esrange (ES) or Sodankylä (SD), of aerosol backscatter ratios (particulate to molecular) at $940 \mathrm{~nm}$ (red curve), colour index $(940 / 480 \mathrm{~nm}$ ) (grey filled), and temperature depression below the threshold for existence of nitric acid trihydrate (blue filled). $T_{\text {NAT }}$ values are calculated using the observed water vapour profiles and assuming 12 ppbv $\mathrm{HNO}_{3}$ consistent with a mean-vortex value, measured by the Envisat-MIPAS instrument late November 2002.

disappear, and most of the profile again consists of type 1a layers.

In the middle of the period, on 4 and 6 December, the main set of observations were performed, consisting of two balloon flights with multi-instrument gondolas for comprehensive in-situ measurements of the chemical and physical properties of PSC particles and characterization of the ambient air environment. Two identical independent gondolas were equipped with the following instrumentation. An aerosol composition mass spectrometer (ACMS) measured the chemical composition of individual PSC particles (Schreiner et al., 1998; Schreiner et al., 1999b). A condensation nuclei $(\mathrm{CN})$ counter and three optical particle counters (OPCs) measured particle size distributions (Deshler et al., 2003). Two OPCs measured the concentration of ambient aerosol in the size range $0.15-10.0 \mu \mathrm{m}$ radius. One of these used a $0.1 \mathrm{~m}$ vertical inlet, pointing up, and the second a $0.1 \mathrm{~m}$ horizontal inlet. The horizontal inlet OPC was added to limit the loss of larger particles to the intake during descent. In practice the descents were slow and the orien- tation of the sampling inlet did not influence the measurements significantly. Measurements from the vertical inlet OPC are presented here. The third OPC was used to measure the concentration of ambient stratospheric sulphate aerosols (SSA) in the same size range. A $1 \mathrm{~m}$ vertical inlet heated to $300 \mathrm{~K}$ was added to this instrument to evaporate condensed water and nitric acid from PSC particles. Outside of a PSC, measurements from this instrument agreed with the ambient aerosol OPCs. A laser backscatter sonde (LABS) (Adriani et al., 1998) and the above mentioned backscatter sonde measured the aerosol backscatter at four wavelengths (480, 532,690 , and $940 \mathrm{~nm}$ ) together with aerosol depolarisation at $532 \mathrm{~nm}$. A frost point hygrometer measured the water vapour concentration in the gas phase (Ovarlez and Ovarlez, 1996), and several sensors on the gondolas measured temperature and pressure. Analyses of particle chemical composition, including the uptake of $\mathrm{HCl}$ in the PSC particles, are presented by Weisser et al. (2004). Gondolas, equipped with identical instrumentation, have previously been flown from Esrange for measurements of PSC properties under mountain wave 

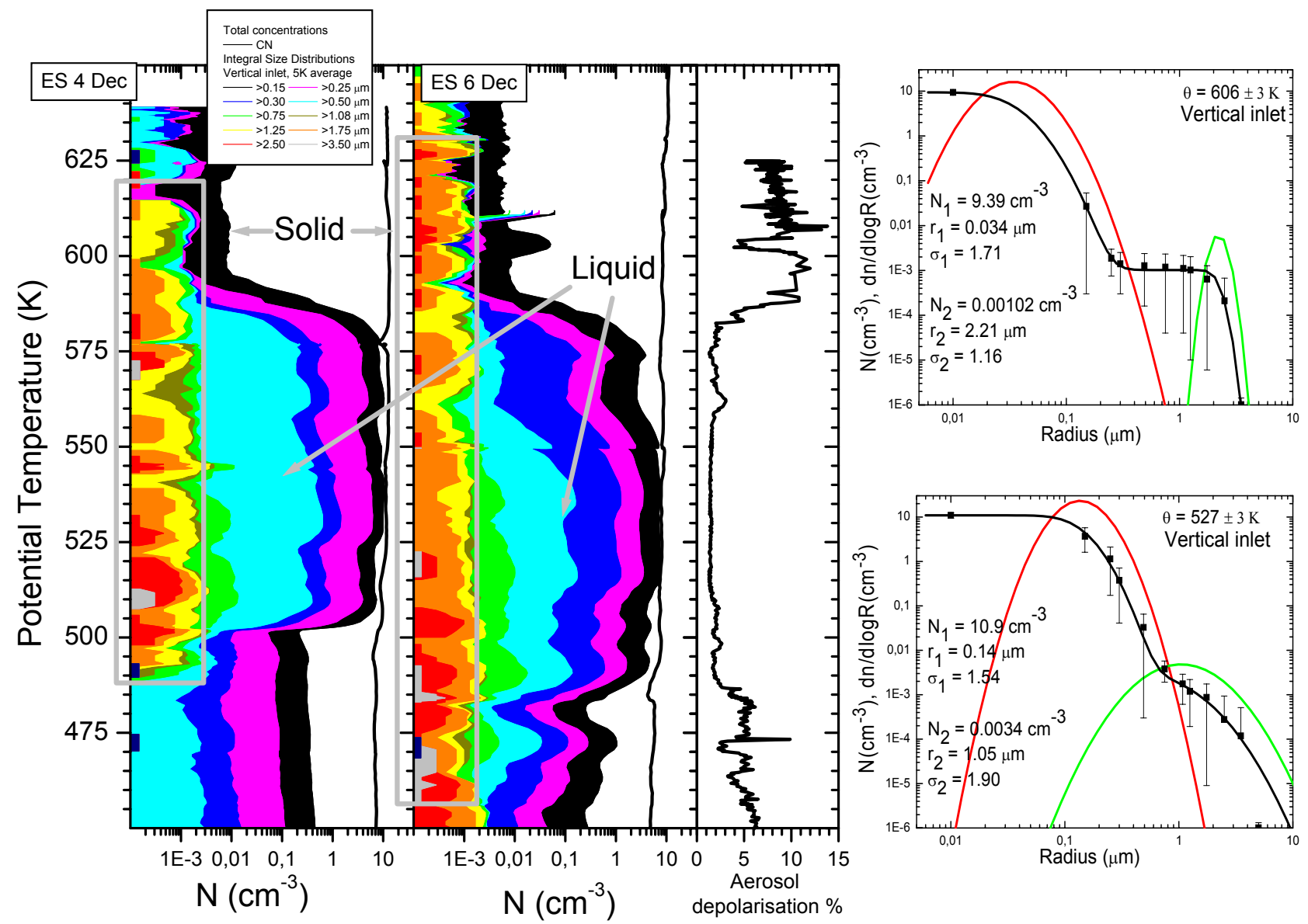

Fig. 2. Integral size distributions, measured by the optical particle counter with vertical inlet, and condensation nucleus concentrations (colour-filled curves and black curve in the two left-hand panels) from the first ascent during gondola-flights from Esrange on 4 and 6 December , 2002. The integral size distributions give the number concentrations of particles with radii larger than the indicated values in the legend. Also shown is the aerosol depolarisation at $532 \mathrm{~nm}$, measured by the LABS on 6 December. The thick liquid particle layers and the solid particle layers above (also seen in Fig. 1) are shown with arrows. The gray boxes indicate the presence of solid particles throughout the vertical profile and mixed in with the thick liquid particle layers. Bimodal lognormal size distributions are fitted to all measured integral size distributions in the two flights. Two examples from 6 December at $527 \mathrm{~K}$ and $606 \mathrm{~K}$ potential temperature are shown in the right-hand panels, giving the differential size distributions $(\mathrm{dn} / \mathrm{d} \operatorname{logR})$ of the two modes as red and green curves. Together the two modes correspond to the integral size distribution (black curve) which fits the measurements (shown with error bars). Lognormal fit parameters appear in the plots.

conditions (Voigt et al., 2000, 2003; Schreiner et al., 2003; Larsen et al., 2002; Deshler et al., 2003).

Integral size distributions, measured by the OPCs during the first ascents on 4 and 6 December through the PSCs, appear in Fig. 2. The figure also shows the aerosol depolarisation ratio, measured with the LABS on 6 December. The thick type $1 \mathrm{~b}$ PSC layers, identified by colour index in Fig. 1, clearly appear with low depolarisation values, roughly between 500 and $580 \mathrm{~K}$ potential temperature, with elevated concentrations of the smallest particle sizes. Within the type $1 \mathrm{~b}$ layer nearly all particles have grown to sizes larger than $0.15 \mu \mathrm{m}$, as the curve for this size class approaches the total particle number concentration, measured by the $\mathrm{CN}$ counter. The ACMS clearly identifies $\mathrm{H}_{2} \mathrm{O}$ and $\mathrm{HNO}_{3}$ as the major components (Weisser et al., 2004). Above and below the thick type $1 \mathrm{~b}$ layer, the type 1a layers appear with high depolarisation, also identified by colour index in Fig. 1. Only a small number concentration $\left(\approx 10^{-3} \mathrm{~cm}^{-3}\right)$ of relatively large particles $(>\approx 1 \mu \mathrm{m})$ are observed while most of the particles have sizes smaller than $0.15 \mu \mathrm{m}$.

An important feature to notice is that the mode in the size distributions with relatively large particles and small number concentrations, characteristic of the upper type 1a layers, appears throughout both vertical profiles, indicated by the gray boxes in Fig. 2. What is interpreted from the backscatter measurements (Fig. 1) as thick type 1b PSC layers appear to be layers of mixed liquid and solid particles. Similar interpretations have been reached from lidar measurements of 
Esrange, 4 and 6 December 2002, all measuremnets
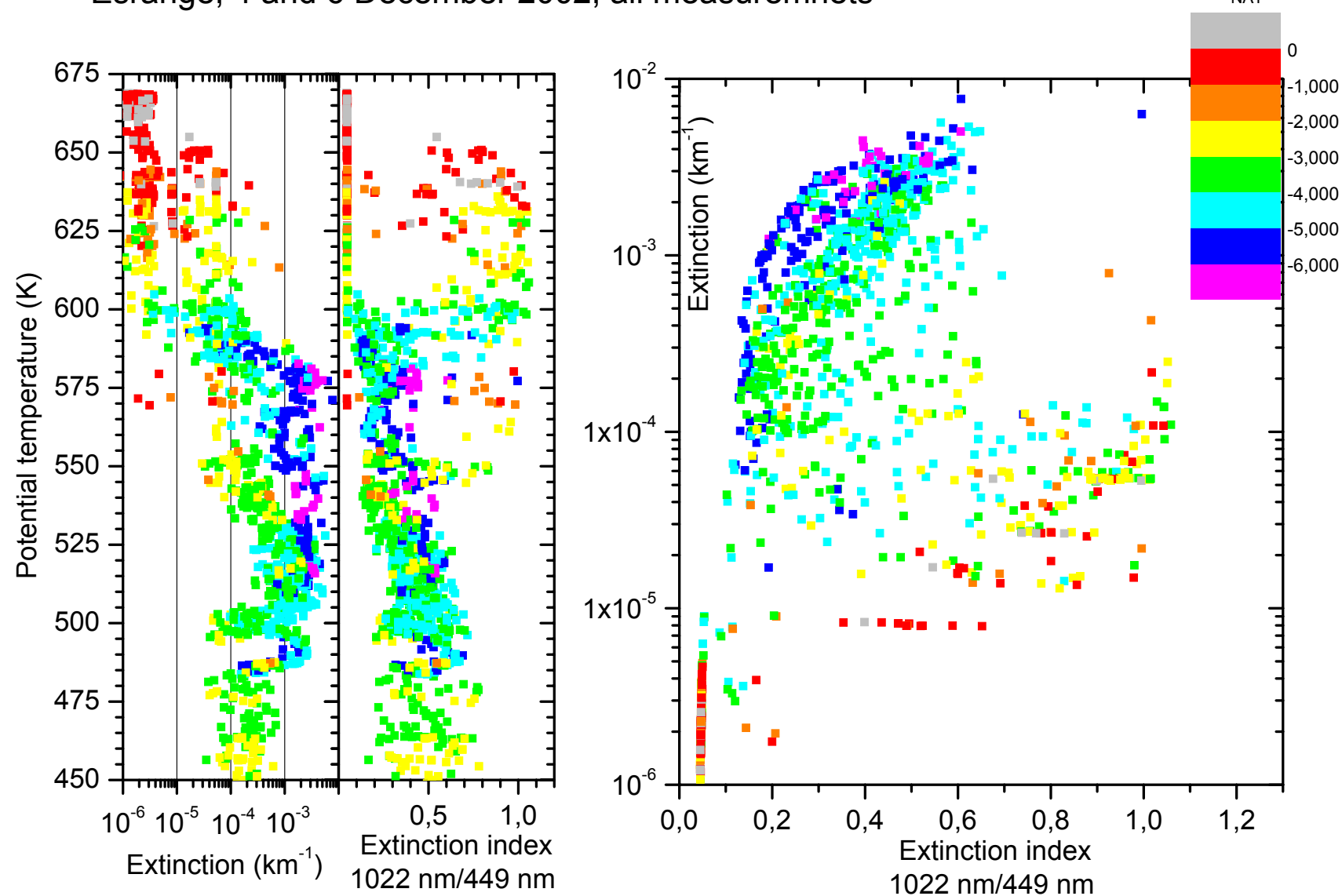

Fig. 3. Calculated profiles (left-hand panels) of extinction at $1022 \mathrm{~nm}$ and extinction index (1022 to $449 \mathrm{~nm}$ ratio), based on measured size distributions with the optical particle counter. The dots have been colour coded according to the temperature depression below $T_{\mathrm{NAT}}$. The panel on the right-hand side gives a scatter plot of extinction at $1022 \mathrm{~nm}$ versus extinction index.

PSCs, e.g. Shibata et al. (1997, 1999), Shibata (1999), Stein et al. (1999), Biele et al. (2001), and Toon et al. (2000). If the large particle mode in our profiles of PSC size distributions was due to liquid particles, this would also be reflected as bimodal size distributions of the background sulphate aerosol, which is not the case as seen in the corresponding OPC measurements with the heated inlet.

When the local temperatures drop below the threshold for STS, roughly $4 \mathrm{~K}$ below $T_{\mathrm{NAT}}$, the majority of the background SSA grow to sizes larger than $0.15 \mu \mathrm{m}$. This is illustrated in the two right-hand panels in Fig. 2, showing examples of bimodal lognormal fits to the measured size distributions in the liquid particle layer at $527 \mathrm{~K}$ potential temperature and in the solid particle layer at $606 \mathrm{~K}$ on 6 December. At the low temperatures in the $527 \mathrm{~K}$ layer, the SSA particles have grown into fully developed STS particles (red curve) with a median radius of $0.14 \mu \mathrm{m}$, representing nearly all particles. A small fraction of the particles reside in the large mode with median radius $1.05 \mu \mathrm{m}$, interpreted as solid particles, and mixed with the liquid particles. The liquid particles dominate the optical properties, giving rise to high backscatter ratios and low colour indices (Fig. 1) and thereby a type $1 \mathrm{~b}$ PSC classification (or what hereafter will be called a liquid particle layer). In the upper layer, where the temperature is just slightly below $T_{\mathrm{NAT}}$, the majority of the particles are SSA, having a small median radius of $0.034 \mu \mathrm{m}$, and the optical properties (low backscatter ratio and high colour index) are dominated by large solid particles and thereby a type 1a PSC classification (or what hereafter will be called a solid particle layer). In both cases the observations actually show mixtures of many liquid particles (either SSA or more highly developed STS, their size being controlled by the local temperature) and a small fraction of larger solid particles. This interpretation is in agreement with an analysis by Drdla et al. (2002b), showing that most stratospheric aerosols are liquid particles, even at the lowest temperature. 


\section{Optical modeling}

Throughout both flights on 4 and 6 December, uni-modal or bi-modal lognormal size distributions have been fitted to the measured integral size distributions as shown in the two examples in Fig. 2. A T-matrix optical model (Mishchenko and Travis, 1998) has been used to calculate, from the size distributions, the expected extinction at 449 and $1022 \mathrm{~nm}$, assuming the small mode to consist of liquid STS particles and the large mode to consist of solid NAT particles. The wavelengths chosen correspond to two of the wavelengths where aerosol extinctions are measured from satellite by the Stratospheric Aerosol and Gas Experiment (SAGE) III (Poole et al., 2003). An extinction (colour) index is defined as the ratio of the 1022 and $449 \mathrm{~nm}$ extinctions.

In the left-hand panels of Fig. 3, profiles of calculated $1022 \mathrm{~nm}$ extinction and extinction index for OPC measurements are shown between 450 and $675 \mathrm{~K}$ potential temperature on 4 and 6 December. The dots in Fig. 3 have been colour coded according to the temperature difference between the measured air temperature and $T_{\mathrm{NAT}}$, using the measured $\mathrm{H}_{2} \mathrm{O}$ profile and assuming $12 \mathrm{ppbv} \mathrm{HNO}_{3}$. The extinction values peak at the lowest air temperatures in the liquid PSC layers roughly between 500 and $580 \mathrm{~K}$ potential temperature with nearly the same values as observed by SAGE III in the same period (Poole et al., 2003). The good agreement with satellite measurements shows that our measurements could be representative for PSC properties in a larger geographical region in the Arctic during the period of investigation.

High extinction indices are mainly calculated at the highest altitudes above $580 \mathrm{~K}$, where the measurements show the presence of solid PSCs. In the right-hand side of Fig. 3 the calculated extinction versus extinction index is plotted. A clear bifurcation in the plot is noticed with one branch going to high extinction values, approaching the top of the branch at the lowest temperatures and corresponding to the liquid PSC layers. Another branch is seen with high extinction indices and moderate extinction at temperatures a few $\mathrm{K}$ below $T_{\mathrm{NAT}}$, corresponding to the observed solid PSCs. Similar bifurcation has been observed in satellite data from the Polar Ozone and Aerosol Measurement (POAM) (Strawa et al., 2002) and in SAGE III data (Poole et al., 2003), demonstrating the ability of satellite extinction measurements to discriminate between dominantly liquid and dominantly solid PSCs in agreement with the results in Fig. 3.

\section{Microphysical simulations}

Air parcel trajectories of the observed PSCs have been calculated based on analyses from the European Centre for Medium Range Weather Forecasts (ECMWF). Examples of 6-day backward temperature histories for the upper solid particle layers and middle liquid particle layers (Fig. 1) appear in
Fig. 4. Due to the absence of mountain leewaves over Scandinavia the temperature histories can be regarded as relatively accurate, at least within a few days prior to the time of observation, which is most important for microphysical simulations. Figure 4 shows that the liquid and solid particle layers have experienced nearly the same temperature history. The main difference is that the liquid particle layers are observed at lower temperatures than the solid particle layers. The solid particles have passed through lower temperatures a few hours prior to the observation. The particles have spent not more than 2.5 days at temperatures below $T_{\mathrm{NAT}}$ in the final cooling before observation. The solid particles have not experienced temperatures below the ice frost point, and in particular not temperatures $3-4 \mathrm{~K}$ below $T_{\text {ice }}$ which is required for ice to freeze homogeneously in STS droplets (Koop et al., 2000).

The formation of solid particles at $606 \mathrm{~K}$ potential temperature on 6 December (cf. right-hand panels in Fig. 2) has been simulated using a detailed microphysical model (Larsen, 2000; Larsen et al., 2002), applying the ECMWF temperature history. The model calculates the time dependent changes in size distributions of liquid sulphate and STS particles, and solid NAT, ice, and sulphuric acid tetrahydrate (SAT) particles together with changes in gas phase $\mathrm{HNO}_{3}$ and $\mathrm{H}_{2} \mathrm{O}$, using the basic vapour diffusion equation and applying a full kinetic approach. Homogeneous volume dependent nucleation of ice $3-4 \mathrm{~K}$ below the ice frost point (Koop et al., 2000) and homogeneous surface dependent nucleation of nitric acid dihydrate (NAD) (Tabazadeh et al., 2002) above $T_{\text {ice }}$ are included in the model, assuming an instantaneous conversion of NAD to NAT particles. The surface nucleation rates have been reduced by a factor 20 as discussed in more detail below.

The model is initialized $240 \mathrm{~h}$ prior to observation when temperatures were above $T_{\mathrm{SAT}}$, using OPC and frost point hygrometer measurements on 6 December at the $606 \mathrm{~K}$ potential temperature level. Measurements from the OPC on the gondola with the vertical inlet, heated to $300 \mathrm{~K}$, indicate the liquid background SSA can be described using a uni-modal lognormal size distribution with number density $N_{t}=9.3 \mathrm{~cm}^{-3}$, median radius $r_{m}=0.07 \mu \mathrm{m}$, and geometric standard deviation $\sigma=1.4$. These parameters differ from those determined for the first mode of the size distribution from unheated inlet OPC measurements at $606 \mathrm{~K}$, Fig. 2. This difference results from the fact that at these altitudes the heated inlet instrument observed only particles $>0.15$, $0.25 \mu \mathrm{m}$, with the concentration of $0.25 \mu \mathrm{m}$ particles significantly below $0.15 \mu \mathrm{m}$ particles, and particles in the next larger size bin below the detection threshold of the instrument. The observations at 0.15 and $0.25 \mu \mathrm{m}$ coupled with $\mathrm{CN}$ provide the three parameters required for a uni-modal lognormal distribution, and the large particle tail of the distribution is well constrained. Within a PSC at these altitudes, however, particles $>0.15 \mu \mathrm{m}$ experience some growth into PSC particles, see Fig. 2, and the concentration of $0.25 \mu \mathrm{m}$ particles increases significanlty over SSA. Since the fitting 
$550 \mathrm{~K}$ potential temperature
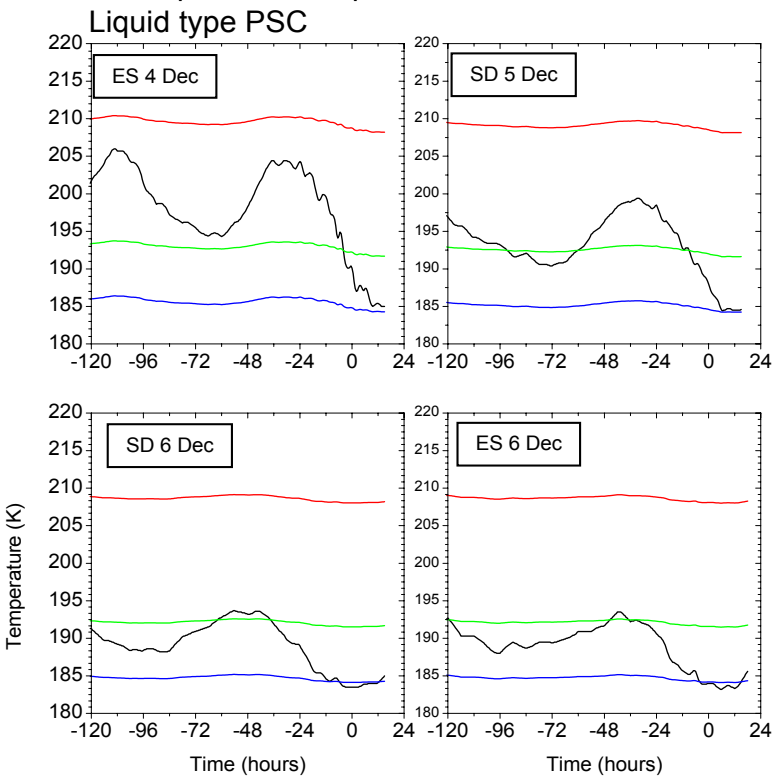

$600 \mathrm{~K}$ potential temperature
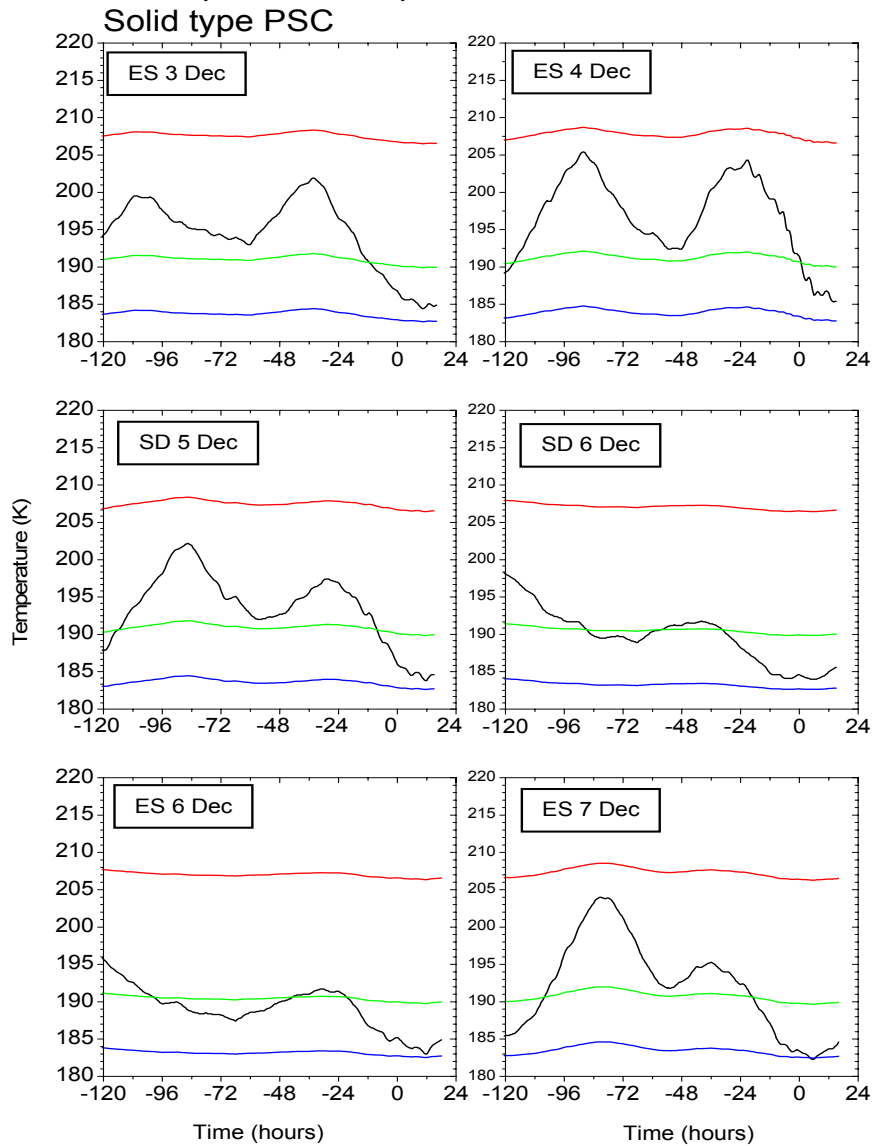

Fig. 4. Six-day temperature histories, based on analyses from ECMWF, in connection with the backscatter soundings shown in Fig. 1 from Esrange (ES) and Sodankylä (SD). The left-hand panels give temperature histories in the liquid particle layers around $550 \mathrm{~K}$ (only observed on 4, 5, and 6 December) and the right-hand panels in the solid particle layers around $600 \mathrm{~K}$ potential temperature. The nearly horizontal curves in each panel give the sulphuric acid tetrahydrate (SAT) melting temperature (red), $T_{\mathrm{NAT}}$ (green), and $T_{\text {ice }}$ (blue), calculated from the measured water vapour concentrations, assuming $12 \mathrm{ppbv} \mathrm{HNO}_{3}$.

algorithm requires three measurements for the first mode size distribution it uses the concentrations at the same three sizes as the heated inlet OPC, but because of growth of particles $>0.15 \mu \mathrm{m}$ in the PSC, the first mode distributions are generally broader with a smaller first mode radii. Thus it is not strictly correct to equate the first mode of the PSC size distribution at $606 \mathrm{~K}$ with SSA. The more correct representation of SSA size distribution is given by measurements from the heated inlet OPC, and these were used to initialize the PSC growth model. The gas phase $\mathrm{H}_{2} \mathrm{O}$ concentration is set to $6 \mathrm{ppmv}$ according to the frost point hygrometer measurements. The initial $\mathrm{HNO}_{3}$ concentration is assumed to be 12 ppbv. This number is consistent with a mean-vortex value, measured by the MIPAS instrument onboard the Envisat satellite late November 2002 and not being influenced by uptake of $\mathrm{HNO}_{3}$ in PSC particles. The actual $\mathrm{HNO}_{3}$ gas phase concentration in the PSC layers was measured with the MIPAS balloon-borne infrared spectrometer on 7 December 2003 from Esrange between 5 and $10 \mathrm{~h}$ after the particle measurements, showing between $\approx 9$ and $\approx 12 \mathrm{ppbv} \mathrm{HNO}_{3}$ at $600 \mathrm{~K}$ potential temperature, depending if the instrument was looking to the north or to the south of the region where the particle measurements were performed. These measurements indicate an uptake of $\mathrm{HNO}_{3}$ in the particles of not more than roughly 2 ppbv at $600 \mathrm{~K}$.

Time dependent results from the simulation are shown in Fig. 5. At time $-18 \mathrm{~h}$, i.e. 1.75 day before observation, the temperature (Panel A) drops below $T_{N A T}$ and around $-4 \mathrm{~h}$ is sufficiently low for the growth of substantial STS volumes (Panel D). The number concentrations in the smaller size classes of the OPC $(<0.5 \mu \mathrm{m}$, Panel C) increase as well as the aerosol backscatter ratio and extinction (Panel B), and the gas phase is depleted in $\mathrm{HNO}_{3}$ (Panel E). Around time $-3 \mathrm{~h}$, the model predicts that small number concentrations of NAT particles are formed by the adopted homogeneous surface nucleation. The NAT volume increases (Panel D) as well as the number concentrations in the large mode in the OPC size classes (Panel C), now forming a bimodal size 


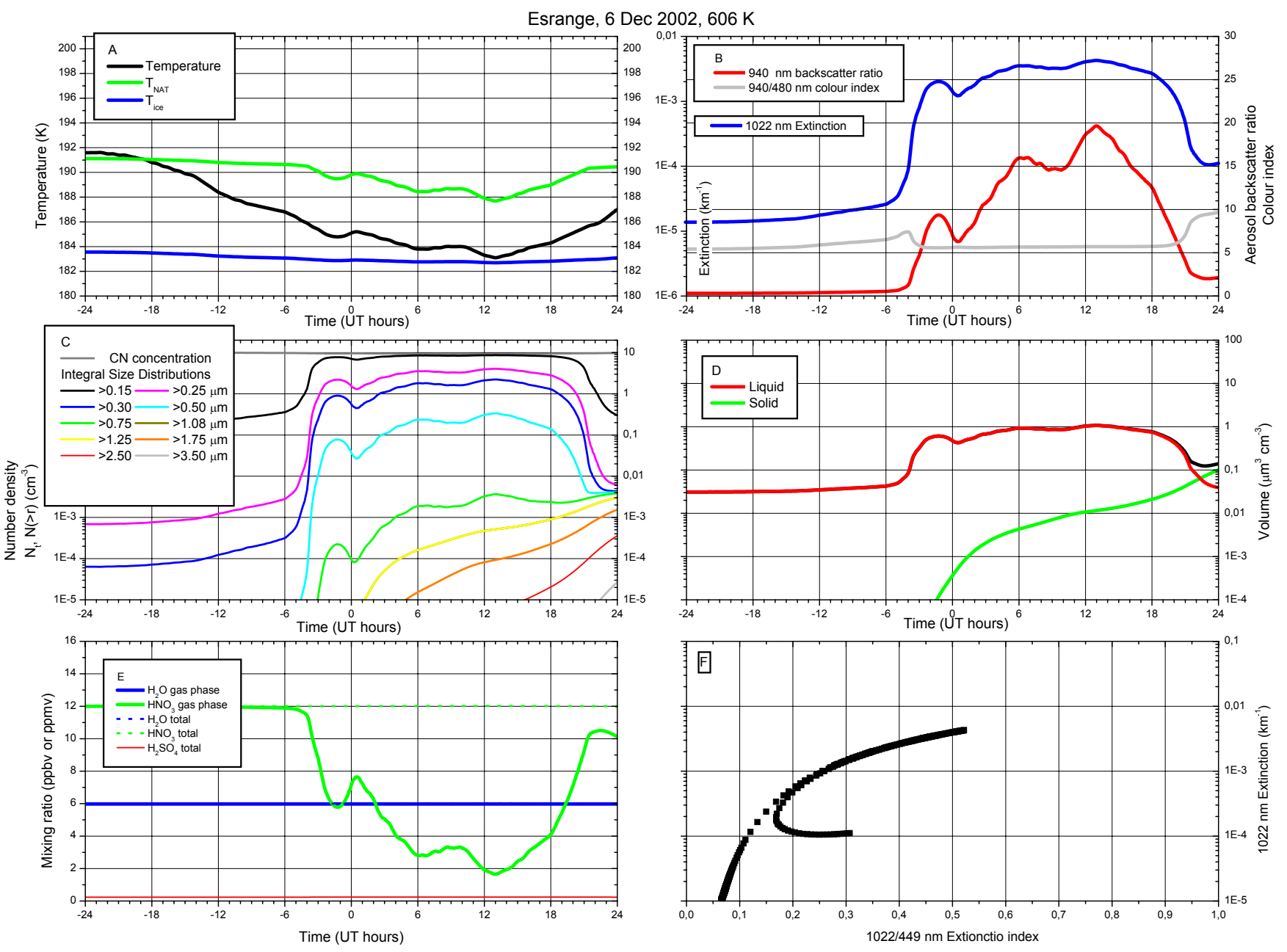

Fig. 5. The last 2 days of the PSC simulation at $606 \mathrm{~K}$ potential temperature. The panels show as functions of time (UT hours on 6 December) (a) air temperature ( $T_{\text {air }}$, black curve), $T_{\mathrm{NAT}}$ (green), $T_{\text {ice }}$ (blue), (b) aerosol backscatter ratio ( $940 \mathrm{~nm}$, red), colour index $(940 / 480 \mathrm{~nm}$, gray) and $1022 \mathrm{~nm}$ extinction, (c) cumulative number concentrations corresponding to the optical particle counter size classes as indicated in the legend, (d) particle volumes of liquid (red) and NAT (green) particles, (e) gas phase and total concentrations of $\mathrm{HNO}_{3}$ (green), $\mathrm{H}_{2} \mathrm{O}$ (blue), $\mathrm{H}_{2} \mathrm{SO}_{4}$ (red), (f) scatter plot of extinction $(1022 \mathrm{~nm})$ versus extinction index $(1022 / 449 \mathrm{~nm})$ for all data in the simulation.

distribution with a small number concentration of solid particles mixed together with the abundant liquid particles. The generated NAT particles continue to grow throughout the rest of the simulation. Until around time $18 \mathrm{~h}$ temperatures are sufficiently low for the total particle volume to be dominated by the STS particles; the backscatter ratio is high and colour index is low (Panel B), and the small mode in the OPC size distribution is shifted to larger sizes. If the particles had been observed at these low temperature conditions, the observations would resemble the liquid PSC particle layers in Figs. 1 and 2 (actually a mixture of liquid and solid particles). Instead, within a few hours before observation, the temperature increases and the liquid particles evaporate, whereas the large solid particles remain nearly unchanged. The backscatter decreases and colour index increases (Panel B) and the cloud appears as a solid particle PSC in good agreement with the observations (Fig. 1). During the evaporation of the liquid particles the gas phase $\mathrm{HNO}_{3}$ increases until the STS particles have disappeared whereas the solid particles continue to grow, again lowering the $\mathrm{HNO}_{3}$, corresponding to a final uptake of $2 \mathrm{ppbv}$ in the particles in good agreement with the MIPAS measurements. Throughout the simulation the solid particles are out of equilibrium.

Panel F in Fig. 5 shows a scatter plot of simulated extinction versus extinction index, corresponding to SAGE-III observations, for every time during the simulation, using the T-matrix model, assuming particles $>1.0 \mu \mathrm{m}$ are NAT and smaller particles are STS. We have applied refractive indices of 1.50 and 1.52 for STS and 1.60 and 1.51 for NAT at the upper and lower SAGE-III wavelengths, assuming an aspect ratio of 1.05 for NAT particles. We note that the calculated extinction only depends weakly on these assumed 

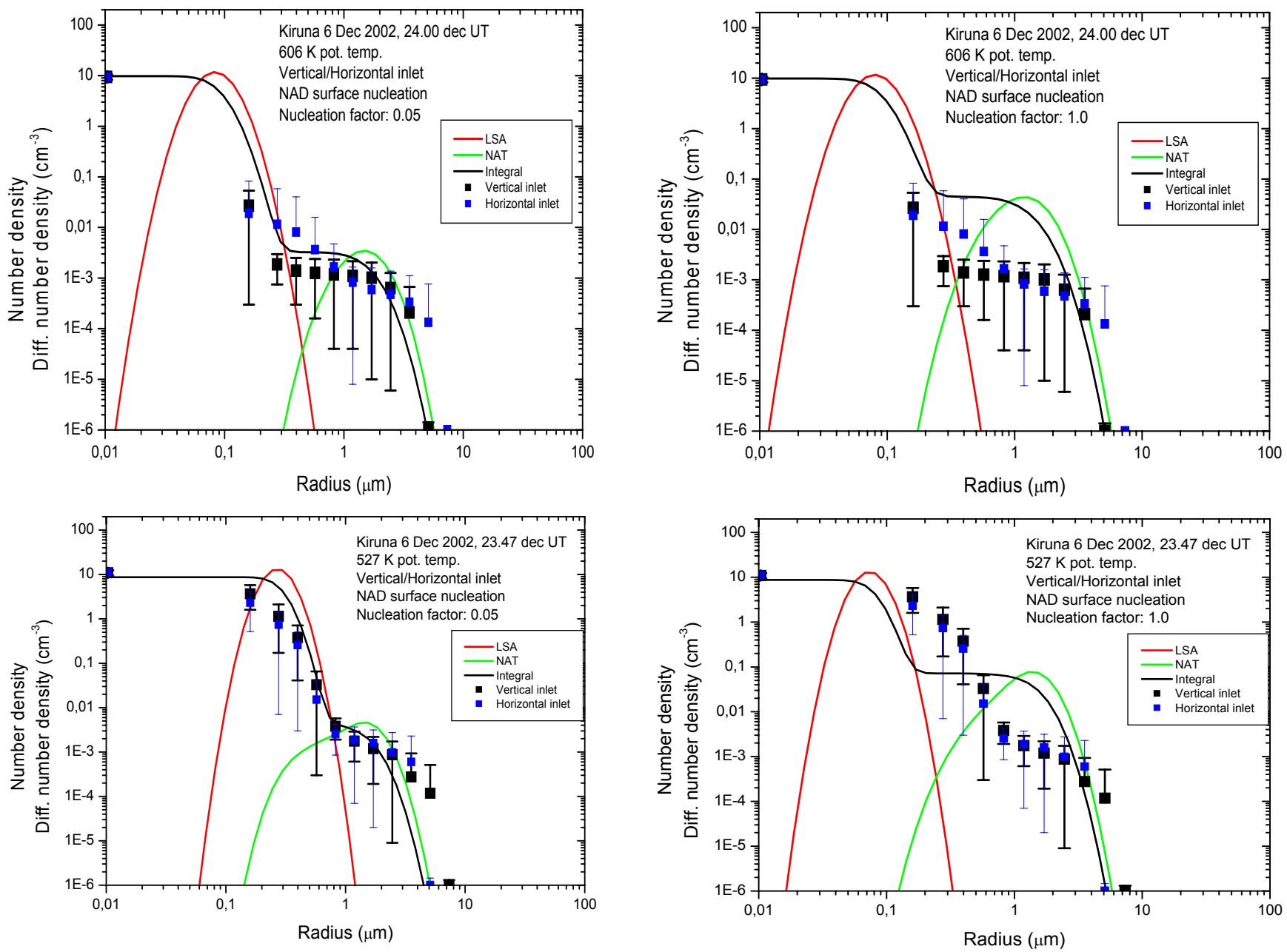

Fig. 6. Calculated differential size distributions of liquid sulphate aerosol (red) and solid NAT PSC (green curve) particles at $606 \mathrm{~K}$ (upper row) and $527 \mathrm{~K}$ potential temperature (lower row). The black curve is the corresponding calculated integral size distribution which can be compared directly to the measured integral size distributions. Simultaneous measurements are shown for both the vertical (black dots with error bars, see also Fig. 2) and horizontal inlets (blue dots) of the two OPCs applied in the experiments. Simulation results are shown, using a nucleation adjustment factor of 0.05 (left-hand column) and with no adjustment (right-hand column) in the homogeneous surface NAD nucleation calculations.

values (Strawa et al., 2002, Mishchenko, 1993). As the liquid particles form, the extinction versus extinction index follows the upper branch until the extinction index slightly exceeds 0.5. During the subsequent STS particle evaporation, and as the solid particles begin to dominate the particle volume, the points shift to the lower branch. As the solid particles continue to grow towards the end of the simulation, the extinction index in the lower branch increases in the diagram with nearly constant extinction. These results are consistent with SAGE-III measurements (Poole et al., 2003).

The final calculated differential size distributions $(\mathrm{dn} / \mathrm{d} \operatorname{logR})$ at $606 \mathrm{~K}$ are shown in the upper left-hand panel in Fig. 6. There are two clearly distinct modes in the size distributions consisting of a background of liquid sulphate aerosols (red curve) with median radius less than $0.1 \mu \mathrm{m}$, the particles on which the liquid STS particles grew, and the
NAT particles with a median radius larger than $1 \mu \mathrm{m}$ (green curve). Together the two differential distributions add up to the integral size distribution (black curve) which can be compared directly to the measured integral size distribution by the two versions of OPC displayed, one equipped with horizontal and one with vertical inlet. The model represents the large mode of the NAT particles quite well.

A similar calculation has been performed for the 6 December case at $527 \mathrm{~K}$ potential temperature in the liquid particle layer (using an initial suphate size distribution with $N_{t}=8 \mathrm{~cm}^{-3}, r_{m}=0.06 \mu \mathrm{m}, \sigma=1.3$ and $\mathrm{H}_{2} \mathrm{O}=5.9 \mathrm{ppmv}$, $\mathrm{HNO}_{3}=12.5 \mathrm{ppbv}$ ) with results presented in the lower lefthand panel in Fig. 6. Here the small particle mode is dominated by STS particles with a median radius around $0.25 \mu \mathrm{m}$ mixed in with the NAT particle mode. Again the model reproduces the measurements reasonably well. At this altitude 
the OPC measurements could be influenced by particles falling in from higher altitudes; a process which is not considered in the model. This is not the case at $606 \mathrm{~K}$ at the top of the PSCs where sedimentation from above is not a factor. The model calculates an $\mathrm{HNO}_{3}$ gas phase concentration at $527 \mathrm{~K}$, corresponding to an uptake in the particles of $6.5 \mathrm{ppbv}$. This value is consistent with the balloon-borne MIPAS measurements in the north looking scan where temperatures allowed the existence of STS particles. MIPAS measurements in the south-looking scan at temperatures above $T_{\mathrm{STS}}$ show an uptake around $2 \mathrm{ppbv}$.

\section{Discussion}

As mentioned above the homogeneous surface nucleation rates for NAD, given by Tabazadeh et al. (2002), have been reduced by a factor 20 (i.e. the nucleation rates have been multiplied by an adjustment factor 0.05 ). If this adjustment had not been made, the model would produce too many solid particles and too few liquid particles in conflict with the OPC measurements. Calculated size distributions without the adjustment (i.e. adjustment factor 1.0) appear in the right-hand panels of Fig. 6 for the $606 \mathrm{~K}$ and $527 \mathrm{~K}$ potential temperature cases. Equally important is the fact that the larger number concentrations of solid particles leads to a much stronger uptake of $\mathrm{HNO}_{3}$ in the particles in conflict with the balloonborne MIPAS measurements. In both cases the model without the nucleation adjustment calculates gas phase concentrations around $1 \mathrm{ppbv}$, i.e. uptake in the particles of around $11 \mathrm{ppbv}$, in contrast to the measurements showing uptake not more than $\approx 2$ and $\approx 7.5 \mathrm{ppb}$ at $606 \mathrm{~K}$ and $527 \mathrm{~K}$ potential temperature, respectively.

Nucleation adjustment factors in the range between 0.05 (as shown in Fig. 6) and 0.1 produce results in reasonable agreement with all measurements. The main difference using the more moderate factor 0.1 is that the shoulder around $1 \mu \mathrm{m}$ in the integral size distribution is shifted to higher number concentrations, the $\mathrm{HNO}_{3}$ uptake in the particles is increased to $3 \mathrm{ppbv}$, and the extinction is slightly increased, moving these results towards somewhat better agreements with SAGE-III measurements (Poole et al., 2003).

A reduction in the surface nucleation rates by a factor between 20 and 10 corresponds to an increase of $\approx 4 \%$ or $\approx 1 \mathrm{kcal} \mathrm{mol}^{-1}$ in the free energy $(\Delta \mathrm{G})$ of formation of a crystal nucleus on the droplet surface, applying the parameterization of $\Delta \mathrm{G}$ by Tabazadeh et al. (2002). As mentioned by the authors, the empirical parameterizations of $\Delta \mathrm{G}$ are based on laboratory nucleation experiments on concentrated, pure aqueous nitric acid, extrapolated to stratospheric conditions with much more dilute solutions. The effect of even small amounts of $\mathrm{H}_{2} \mathrm{SO}_{4}$ has not been considered. Maintaining the caveats of the extrapolations, an increase of $\approx 4 \%$ in the free energy would correspond to a reduction in the $\mathrm{HNO}_{3}$ mole fraction of the surface of about $20 \%$ according to the applied parameterization.

It appears from the observations that solid particles with number concentrations on the order of $10^{-3}$ per $\mathrm{cm}^{3}$ of air are produced in less than 1.75 day, resulting in a hydrate particle production rate of at least $7 \times 10^{-9} \mathrm{~cm}^{-3}$ (air) s${ }^{-1}$, if only temperatures below $T_{\mathrm{NAT}}$ are required, increasing the production rate above $10^{-8} \mathrm{~cm}^{-3}$ (air) $\mathrm{s}^{-1}$ if temperatures have to go below $T_{\mathrm{STS}}$ before the onset of nucleation. Assuming these hydrate particles form by homogeneous nucleation would require production rates orders of magnitude higher than derived from laboratory experiments (Knopf et al., 2002). We have applied the surface nucleation mechanism of Tabazadeh et al. (2002) because this, to our knowledge, is the latest published available parameterisation of hydrate nucleation out of STS working at temperature above the ice frost point. Secondly, the surface nucleation seems more consistent with laboratory experiments (Tabazadeh et al., 2002), compared to a corresponding volume nucleation parameterisation (Tabazadeh et al., 2001; Salcedo et al., 2001). However, we have also made simulations with the latter volume-proportional nucleation and could obtain equally good agreement with the observations if these nucleation rates were increased by a factor 10 . Hence, the observations and microphysical simulations presented here may not clarify whether surface or volume nucleation or heterogeneous nucleation (Drdla et al., 2002a) is responsible for the observed high hydrate production rate, an issue which would require further particle nucleation experiments in the laboratory.

The model results are not highly sensitive to the accuracy of the temperature history. Adding a constant temperature correction of $-1 \mathrm{~K}$ to $+1.5 \mathrm{~K}$ in the $606 \mathrm{~K}$ case, which is within the estimated accuracy of the analyzed ECMWF temperatures (Knudsen, 2003), the model still produces results in good agreement with the observations. A reduction in temperature increases the width of the solid particle size distribution (higher number of the smallest solid particles), but reduces the median radius, whereas an increase in temperature has the opposite effect. Increasing the temperatures between $+1.5 \mathrm{~K}$ and $+2.7 \mathrm{~K}$ would gradually decrease the number concentrations of solid particles from slightly above $10^{-3} \mathrm{~cm}^{-3}$ to less than $10^{-5} \mathrm{~cm}^{-3}$, bringing the resultant size distribution in disagreement with the observations, but demonstrating a potential scenario for generating a small number concentration of solid particles with radii around $2 \mu \mathrm{m}$. Such particles could grow to larger sizes within days if temperature stays below $T_{\mathrm{NAT}}$.

If the simulation of early winter PSC formation (not being influenced by mountain leewaves) as shown in Fig. 5 represents real processes in the atmosphere, it would mean that synoptic scale solid PSC particles are formed in quasi co-existence with liquid PSC particles at temperatures below $T_{\mathrm{STS}}$, and that solid PSC particles emerge downwind of the cold region after the evaporation of STS particles at 
temperatures between $T_{\mathrm{STS}}$ and $T_{\mathrm{NAT}}$. There are previous indications from lidar observations of such synoptic scale liquid to solid type PSC transitions (Toon et al., 2000). The scenario is also in agreement with analyses of POAM III satellite data, indicating dominance of solid PSC particles on the eastern side (downwind) of the cold pool axis (Fromm et al., 2003). The scenario would also mean that synoptic scale solid PSCs in general would be observed in air parcels which have spent a longer time at temperatures below $T_{\mathrm{NAT}}$ than air parcels where liquid type PSC are observed; conditions which are in agreement with observations (e.g. Tabazadeh et al., 1996; Larsen et al., 1997, Toon et al., 2000).

The applied surface freezing process implies a highly selective nucleation of hydrate particles, allowing only a small number of particles to grow to large sizes in a solid state whereas the smaller particles remain liquid in agreement with previous findings from the Arctic winter 1999-2000 (Drdla et al., 2002b). According to the scenario presented in Fig. 5, pure liquid PSCs with a uni-modal size distribution would only exist initially in a narrow temperature range and thereby for a relatively short time before the onset of hydrate nucleation and the development of a mixed phase cloud with a bimodal distribution. Lidar observations have indicated a smaller presence of pure liquid clouds than the presence of mixed phase or solid type PSCs (Toon et al., 2000). However, the discrimination between pure liquid clouds and mixed liquid/solid phase clouds in lidar measurements could be difficult and may require depolarization measurements in the near-infrared (Toon et al., 2000). A large mode, mixed into an apparent liquid type PSC, has previously been observed in early winter 1994/95 from Ny Ålesund by Hayashi et al. (1998) and also seen in some, but not all, non-depolarizing liquid particle layers in observations from Andoya (Deshler et al., 2000). Bi-modal size distributions are seen in PSC measurements from Antarctica (e.g. Hofmann and Deshler, 1991), but the physical state and temperature histories are uncertain here. Lidar measurements from Antarctica have also been interpreted as mixed phase clouds (Gobbi et al., 1998). A large mode in liquid particle size distributions have been noted in previous measurements from Kiruna (Schreiner et al., 2003; Deshler et al., 2003), but the formation mechanism could be different in these cases under the influence of mountain leewaves.

\section{Conclusions}

Polar stratospheric clouds, formed in synoptic-scale low temperature regions, not influenced by mountain leewaves, have been observed in a series of balloon-borne measurements from Esrange and Sodankylä in early December, shortly after the first onset of PSC formation in winter 2002/2003. The measurements have shown the development of the characteristic "sandwich" structure with layers of solid particles above and below a thick layer of liquid particles. The liquid lay- ers, however, appear to contain a small abundance of solid PSC particles with nearly the same concentrations as in the surrounding upper and lower layers. It appears that the liquid layers are controlled by local temperatures. When the temperatures, typically in the middle of the PSC layers between 20 and $27 \mathrm{~km}$, are below the threshold for STS, the liquid stratospheric aerosols particles grow into fully developed STS particles. In many optical measurements the layer will appear as a liquid particle layer even though it may contain mixtures of solid particles. The solid particles at the top and bottom at higher temperatures and the solid particles, mixed in with the liquid layers, are nearly unaffected as long as temperatures are below $T_{\mathrm{NAT}}$.

Good agreement is found between measured and calculated optical properties, assuming the PSCs to be composed of mixtures of liquid and solid particles, confirming the ability to discriminate in satellite extinction measurements between PSCs dominated by either liquid or solid particles.

Neither the observed solid PSC at high altitudes, nor the solid particles mixed into liquid particle layers, have experienced temperatures below $T_{i c e}$, but could have formed by selective homogeneous nucleation of NAD or NAT above the ice frost point. Of course we cannot rule out that the solid particles formed by heterogeneous nucleation (Drdla et al., 2002a). However, good results in microphysical simulations of the PSC formation in comparison with measured size distributions, optical properties, and gas phase concentrations are obtained using the surface nucleation by Tabazadeh et al. (2002) and applying a reduction factor of 10-20 in the nucleation rates. If this selective nucleation mechanism is a real process in the atmosphere, it would imply that most synoptic scale liquid PSCs actually contain a small mixture of solid particles. When the liquid particles evaporate downwind of the synoptic scale cold regions, solid PSC particles with low number concentrations should emerge as long as temperatures stay below $T_{\mathrm{NAT}}$.

Acknowledgements. We would like to thank the team from Centre National d'Etude Spatiales, especially the late P. Faucon, for excellent handling of the balloon-flights, and people from the Swedish Space Corporation at Esrange for their efficient support to the experiments. We would like to extend our thanks to the European Space Agency for early provision of MIPAS-Envisat $\mathrm{HNO}_{3}$ profiles. The T-matrix code has been obtained from M. I. Mishchenko's web site. B. P. Luo and C. Voigt are acknowledged for their contributions in establishing a T-matrix expansion coefficient data base. This work was supported by the EU Commission projects CIPA (contract EVK2-CT-2000-00095) and MAPSCORE (contract EVK2-CT-2000-00072), the German Bundesministerium für Bildung und Forschung (BMBF, AFO-2000) POSTA project, the US National Science Foundation (contract OPP- 0095158), and the Danish National Science Foundation.

Edited by: K. Carslaw 


\section{References}

Adriani, A., Cairo, F., Mandolini, S., Di Donfrancesco, G., Deshler, T., and Nardi, B.: A new joint balloon-borne experiment to study Polar Stratospheric Clouds: Laser Backscatter Sonde and Optical Particle Counter, in Proceedings of XVIII Quadrennial Ozone Symposium, L'Aquila 1996, Atmospheric Ozone, edited by Bojkov, R. D. and Visconti, G., 2, 879-882, Edigrafital for Parco Sci. e Tecnol. d'Abruzzo, L'Aquila, Italy, 1998.

Biele, J., Tsias, A., Luo, B. P., Carslaw, K. S., Neuber, R., Beyerle, G., and Peter, T.: Nonequilibrium coexistence of solid and liquid particles in Arctic stratospheric clouds, J. Geophys. Res., 106, 22 991-23 007, 2001.

Browell, E. V., Butler, C. F., Ismail, S., Robinette, P. A., Carter, A. F., Higdon, N. S., Toon, O. B., Schoeberl, M. R., and Tuck, A. F.: Airborne Lidar Observations in the Wintertime Arctic Stratosphere: Polar Stratospheric Clouds, Geophys. Res. Lett., 17, 385-388, 1990.

Carslaw, K. S., Luo, B. P., Clegg, S. L., Peter, T., Brimblecombe, P., and Crutzen, P. J.: Stratospheric aerosol growth and $\mathrm{HNO}_{3}$ gas phase depletion from coupled $\mathrm{HNO}_{3}$ and water uptake by liquid particles, Geophys. Res. Lett., 21, 2479-2482, 1994.

Carslaw, K. S., Wirth, M., Tsias, A., Luo, N. P., Dörnbrack, A., Leutbecher, M., Volkert, H., Renger, W., Bacmeister, J. T., and Peter, T.: Particle microphysics and chemistry in remotely observed mountain polar stratospheric clouds, J. Geophys. Res., 103, 5785-5796, 1998.

Carslaw, K. S., Kettleborough, J. A., Northway, M. J., Davies, S., Gao, R., Fahey, D. W., Baumgardner, D. G., Chipperfield, M. B., and Kleinböhl, A.: A vortex-scale simulation of the growth and sedimentation of large nitric acid hydrate particles, J. Geophys. Res., 107, D20, 8300, doi:10.1029/2001JD000467, 2002.

Deshler, T., Nardi, B., Adriani, A., Cairo, F., Hansen, G., Fierli, F., Hauchecorne, A., and Pulvirenti, L.: Determining the index of refraction of polar stratospheric clouds above Andoya $\left(69^{\circ} \mathrm{N}\right)$ by combining size-resolved concentration and optical scattering measurements, J. Geophys. Res., 105, 3943-3953, 2000.

Deshler, T., Larsen, N., Weisser, C., Schreiner, J., Mauersberger, K., Cairo, F., Adriani, A., Di Donfrancesco, G., Ovarlez, J., Ovarlez, H., Blum, U., Fricke, K. H., and Dörnbrack, A.: Large nitric acid particles at the top of an Arctic stratospheric cloud, J. Geophys. Res., 108, 10.1029/2003JD0003479, 2003.

Drdla, K., Schoeberl, M. R., and Browell, E. V.: Microphysical modelling of the 1999-2000 Arctic winter: 1. Polar stratospheric clouds, denitrification, and dehydration, J. Geophys. Res., 107, 8312, doi:10.1029/2001JD000782, 2002a.

Drdla, K., Gandrud, B. W., Baumgardner, D., Wilson, J. C., Bui, T. P., Hurst, D., Schauffler, S. M., Jost, H., Greenblatt, J. B., and Webster, C. R.: Evidence for the widespread presence of liquidphase particles during the 1999-2000 Arctic winter, J. Geophys. Res., 107, 8318, doi:10.1029/2001JD001127, 2002 b.

Fahey, D. W., Kelly, K. K., Kawa, S. R., Tuck, A. F., Loewenstein, M., Chan, K. R., and Heidt, L. E.: Observations of denitrification and dehydration in the winter polar stratospheres, Nature, 344, 321-324, 1990.

Fahey, D., Gao, R. S., Carslaw, K. S., et al.: The detection of large $\mathrm{HNO}_{3}$-containing particles in the winter Arctic stratosphere, Science, 291, 1026-1031, 2001.

Fromm, M., Bevilacqua, R., Alfred, J., Strawa, T., Hoppel, K., Lumpe, J., Randall, C., and Shaw, C.: An Analysis of Synoptic and Small-scale Forcing of PSCs Observed by POAM III During SOLVE II/ VINTERSOL, results presented at the SOLVE II/VINTERSOL Joint Science Team meeting, Orlando, 21-24 October, 2003.

Fueglistaler, S., Luo, B. P., Voigt, C., Carslaw, K. S., and Peter, T.: NAT-rock formation by mother clouds: a microphysical model study, Atmos. Chem. Phys., 2, 93-98, 2002,

SRef-ID: 1680-7324/acp/2002-2-93.

Gobbi, G. P., Di Donfrancesco, G., and Adriani, A.: Physical properties of stratospheric clouds during the Antarctic winter 1995, J. Geophys. Res., 103, 10 859-10 873, 1998.

Hanson, D. and Mauersberger, K.: Laboratory Studies of the Nitric Acid Trihydrate: Implications for the South Polar Stratosphere, Geophys. Res. Lett., 15, 855-858, 1988.

Hayashi, M., Iwasaka, Y., Watanabe, M., Shibata, T., Fujiwara, M., Adachi, H., Sakai, T., Nagatani, M., Gernandt, H., Neuber, R., and Tsuchiya, M.: Size and number concentration of liquid PSCs: Balloon-borne measurements at Ny Ålesund, Norway in winter 1994/1995, J. Meteorol. Soc. Japan, 76, 549-560, 1998.

Hofmann, D. J. and Deshler, T.: Stratospheric Cloud Observations During Formation of the Antarctic Ozone Hole in 1989, J. Geophys. Res., 96, 2897-2912, 1991.

Knopf, D. A., Koop, T., Luo, B. P., Weers, U. G., and Peter, T.: Homogeneous nucleation of NAD and NAT in liquid stratospheric aerosols: insufficient to explain denitrification, Atmos. Chem. Phys. 2, 207-214, 2002.

Knudsen, B. M.: On the accuracy of analysed low temperatures in the stratosphere, Atmos. Chem. Phys., 3, 1759-1768, 2003, SRef-ID: 1680-7324/acp/2003-3-1759.

Koop, T., Luo, B., Tsias, A., and Peter, T.: Water activity as the determinant for homogeneous ice nucleation in aqueous solutions, Nature, 406, 611-614, 2000.

Larsen, N., Knudsen, B. M., Rosen, J. M., Kjome, N. T., Neuber, R., and Kyrö, E.: Temperature histories in liquid and solid polar stratospheric cloud formation, J. Geophys. Res., 102, 23 50523 517, 1997.

Larsen, N.: Polar Stratospheric Clouds, Microphysical and Optical Models, DMI Scientific Report 00-06, 2000.

Larsen, N., Høyer Svendsen, S., Knudsen, B. M., Voigt, C., Weisser, C., Kohlmann, A., Schreiner, J., Mauersberger, K., Deshler, T., Kröger, C., Rosen, J. M., Kjome, N. T., Adriani, A., Cairo, F., Di Donfrancesco, G., Ovarlez, J., Ovarlez, H., Dörnbrack, A., and Birner, T.: Microphysical mesoscale simulations of polar stratospheric cloud formation constrained by in-situ measurements of chemical and optical cloud properties, J. Geophys. Res., 107, 10.1029/2001JD000999, 2002.

Mann, G. W., Davies, S., Carslaw, K. S., Chipperfield, M. P., and Kettleborough, J.: Polar vortex concentricity as a controlling factor in Arctic denitrification, J. Geophys. Res., 107, D22, 4663, doi:10.1029/2002JD002102, 2002.

Mishchenko, M. I.: Light scattering by size-shape distributions of randomly oriented axially symmetric particles of a size comparable to a wavelength, Appl. Opt., 32, 4652-4666, 1993.

Mishchenko, M. I. and Travis, L.: Capabilities and limitations of a current Fortran implementation of the T-matrix method for ranmomly oriented, rotationally symmetric scatterers, J. Quant. Spectrosc. Radiat. Transfer, 60, 309-324, 1998.

Ovarlez, J. and Ovarlez, H.: Water vapour and aerosol measurements during SESAME, and the observation of low water vapour 
content layers, Polar stratospheric ozone, edited by Pyle, J. A., Harris, N. R. P., and Amanatidis, G. T., Proceedings of the third European workshop, Schliersee, 18-22 September 1995, Air Pollution Research Report no. 56, European Commission, 205-208, 1996.

Poole, L. R. and McCormick, M. P.: Polar Stratospheric Clouds and the Antarctic Ozone Hole, J. Geophys. Res., 93, 8423-8430, 1988.

Poole, L. R., Trepte, C. R., Harvey, V. L., Toon, G. C., and VanValkenburg, R. L.: SAGE III observations of Arctic polar stratospheric clouds, December 2002, Geophys. Res. Lett., 30, 23, 2216, doi:10.1029/2003GL018496, 2003.

Popp, P. J., Northway, M. J., Holecek, J. C., et al.: Severe and extensive denitrification in the 1999-2000 Arctic winter stratosphere, Geophys. Res. Lett., 28, 2875-2878, 2001.

Rosen, J. M. and Kjome, N. T.: Backscattersonde: a new instrument for atmospheric aerosol research, Appl. Opt. 30, 15521561, 1991.

Salcedo, D., Molina, L. T., and Molina, M. J.: Homogeneous freezing of concentrated aqueous nitric acid solutions at polar stratospheric temperatures, J. Phys. Chem. A, 105, 1433-1439, 2001.

Schreiner, J., Voigt, C., Mauersberger, K., McMurry, P., and Ziemann, P.: Aerodynamic Lens System for Producing Particle Beams at Stratospheric Pressures, Aeros. Sci. Tech., 29, 50-56, 1998.

Schreiner, J., Voigt, C., Kohlmann, A., Arnold, F., Mauersberger, K., and Larsen, N.: Chemical analysis of polar stratospheric cloud particles, Science, 283, 968-970, 1999a.

Schreiner, J., Schild, U., Voigt, C., and Mauersberger, K.: Focussing of aerosols into a particle beam at pressures from 10 to 150 Torr, Aerosol Sci. Technol., 31, 373-382, 1999b.

Schreiner, J., Voigt, C., Kohlmann, A., Mauersberger, K., Deshler, T., Kroger, C., Larsen, N., Adriani, A., Cairo, F., Di Donfrancesco, G., Ovarlez, J., Ovarlez, H., Dörnbrack, A., Rosen, J. M., and Kjome, N. T.: Chemical, microphysical, and optical properties of polar stratospheric clouds, J. Geophys. Res., 108, D5, 8313, doi:10.1029/2001JD000825, 2003.

Shibata, T., Iwasaka, Y., Fujiwara, M., Hayashi, M., Nagatani, M., Shiraishi, K., Adachi, H., Sakai, T., Susumu, K., and Nakura, Y.: Polar stratospheric clouds observed by lidar over Spitsbergen in the winter 1994/1995: Liquid particles and vertical "Sandwich" structure, J. Geophys. Res., 102, 10 829-10 840, 1997.

Shibata, T., Shiraishi, K., Adachi, H., Iwasaka, Y., and Fujiwara, M.: On the lidar-observed sandwich structure of polar stratospheric clouds (PSCs) 1. Implications for the mixing state of the PSC particles, J. Geophys. Res., 104, 21 603-21 611, 1999.

Shibata, T.: On the lidar-observed sandwich structure of polar stratospheric clouds (PSCs) 2. Numerical simulations of externally mixed PSC particles, J. Geophys. Res., 104, 21 613-21 619, 1999.

Stein, B., Wedekind, C., Wille, H., Immler, F., Müller, H., Wöste, L., del Guasta, M., Morandi, M., Stefanutti, L., Antonelli, A., Agostini, P., Rizi, V., Readelli, G., Mitev, V., Matthey, R., Kivi, R., and Kyrö, E.: Optical classification, existence temperatures, and coexistence of different polar stratospheric cloud types, J. Geophys. Res., 104, 23 983-23 993, 1999.
Strawa, A. W., Drdla, K., Fromm, M., Pueschel, R. F., Hoppel, K. W., Browell, E. V., Hamill, P., and Dempsey, D. P.: Distriminating Types Ia and Ib stratospheric clouds in POAM satellite data, J. Geophys Res., 107, doi:10.1029/2001JD000458, 2002.

Tabazadeh, A., Turco, R. P., Drdla, K., and Jacobson, M. Z.: A study of Type I polar stratospheric cloud formation, Geophys. Res. Lett., 21, 1619-1622, 1994.

Tabazadeh, A., Toon, O. B., Gary, B. L., Bacmeister, J. T., and Schoeberl,1 M. R.: Observational constraints on the formation of Type 1a polar stratospheric clouds, Geophys. Res. Lett., 23, 2109-2112, 1996.

Tabazadeh, A., Jensen, E. J., Toon, O. B., Drdla, K., Schoeberl, M. R.: Role of the stratospheric freezing belt in denitrification, Science, 291, 2591-2594, 2001.

Tabazadeh, A., Djikaev, Y. S., Hamill, P., and Reiss, H.: Loboratory evidemce for surface nucleation of solid polar stratospheric cloud particles, J. Phys. Chem. A, 106, 10 238-10 246, 2002.

Tabazadeh, A.: Commentary on "Homogeneous nucleation of NAD and NAT in liquid stratospheric aerosols: insufficient to explain denitrification" by Knopf et al., Atmos. Chem. Phys., 3, 863865, 2003,

SRef-ID: 1680-7324/acp/2003-3-863.

Toon, O. B., Browell, E. V., Kinne, S., and Jordan, J.: An Analysis of Lidar Observations of Polar Stratospheric Clouds, Geophys. Res. Lett., 17, 393-396, 1990.

Toon, O. B., Tabazadeh, A., Browell, E. V., and Jordan, J.: Analysis of lidar observations of Arctic polar stratospheric clouds during January 1989, J. Geophys. Res., 105, 20 589-20 615, 2000.

Tsias, A., Wirth, M., Carslaw, K. S., Biele, J., Mehrtens, H., Reichardt, J., Wedekind, C., Weiß, V., Renger, W., Neuber, R., von Zahn, U., Stein, B., Santacesaria, V., Stefanutti, L., Fierli, F., Bacmeister, J., and Peter, T.: Aircraft lidar observations of an enhanced type 1a polar stratospheric clouds during APEPOLECAT, J. Geophys. Res., 104, 23 961-23 969, 1999.

Voigt, C., Schreiner, J., Kohlmann, A., Zink, P., Mauersberger, K., Larsen, N., Deshler, T., Kröger, C., Rosen, J., Adriani, A., Cairo, F., Di Donfrancesco, G., Viterbini, M., Ovarlez, J., Ovarlez, H., David, C., and Dörnbrack, A.: Nitric acid trihydrate (NAT) in polar stratospheric cloud particles, Science, 290, 1756-1758, 2000.

Voigt, C., Larsen, N., Deshler, T., Kröger, C., Schreiner, J., Mauersberger, K., Luo, B. P., Adriani, A., Cairo, F., Di Donfrancesco, G., Ovarlez, J., Ovarlez, H., Dörnbrack, A., Knudsen, B., and Rosen, J.: In situ mountain-wave polar stratospheric cloud measurements: Implications for nitric acid trihydrate formation, J. Geophys. Res., 108, D5, doi:10.1029/2001JD001185, 2003.

Weisser, C., Mauersberger, K., Schreiner, J., Larsen, N., Cairo, F., Adriani, A., Ovarlez, J., and Deshler, T.: Composition analysis of liquid particles in the Arctic stratosphere, Atmos. Chem. Phys. Discuss., 4, 2513-2531, 2004,

SRef-ID: 1680-7375/acpd/2004-4-2513.

World Meteorological Organization (WMO), Scientific assessment of ozone depletion: 2002, Global Ozone Res. and Monitoring Project - Report No. 47, 498, Geneva, 2003. 